\title{
FAKTOR RISIKO KEJADIAN DISLIPIDEMIA PADA LANSIA (Studi Kasus Kontrol Pada Lansia di Poli Lansia RSUD. Bangkinang Kabupaten Kampar Tahun 2016 - 2017)
}

\author{
Risk Factors of Dislipidemia Events in Elderly \\ (Case Study of Control in the Elderly in Elderly Polyclinic Bangkinang Hospital \\ Kampar Regency 2016 - 2017)
}

\author{
Ayuning Lestari ${ }^{1}$, Myrnawati Crie Handini ${ }^{2}$, Taruli Rohana Sinaga ${ }^{2}$ \\ ${ }^{1}$ Mahasiswa Program Studi Magister Ilmu Kesehatan Masyarakat \\ ${ }^{2}$ Staf Pengajar Direktorat Pascasarjana Universitas Sari Mutiara Indonesia \\ E-mail : ayuninglestari17@gmail.com
}

\begin{abstract}
Abstrak
Berdasarkan data dari Badan Pusat Statistik 2014, populasi lansia mencapai 20,24 juta jiwa, setara dengan $8,03 \%$ dari seluruh penduduk Indonesia. Semakin tua usia seseorang, maka semakin rentan terhadap penyakit degeneratif, salah satunya Dislipidemia. Penelitian ini bertujuan untuk mengetahui faktor risiko kejadian Dislipidemia serta menentukan nilai Odds Ratio faktor risiko terhadap Dislipidemia. Desain penelitian ini adalah Case Control Study. Data diperoleh dari catatan rekam medis pasien serta dengan pengukuran langsung kepada responden. Besar sampel dalam penelitian ini adalah 135 responden, 45 responden dari kelompok kasus dan 90 responden dari kelompok kontrol. Hasil analisis bivariat menunjukkan bahwa semua variabel independen berhubungan dengan kejadian Dislipidemia $(\mathrm{p}<0,05)$. Berdasarkan hasil analisis Multivariat variabel yang paling dominan terhadap kejadian Dislipidemia adalah kebiasaan Merokok dengan p-value 0,000 (p-value<0,05) dan nilai OR sebesar 9,929 (95\% CI 3,428-28,762). Disimpulkan bahwa kebiasaan merokok merupakan faktor risiko yang sangat berpengaruh terhadap kejadian Dislipidemia pada lansia.
\end{abstract}

Kata Kunci : Lansia, Dislipidemia, Jenis Kelamin, Obesitas, Diabetes Melitus, Rokok.

\begin{abstract}
Based on the data from the Central Bureau of Statistics in 2014, the population of the elderly reached 20.24 million or $8.03 \%$ of the whole Indonesian people. The older a person is, the more vulnerable he is to degenerative diseases, and one of them is dyslipidemia. The objective of the research was to find out the risk factor for the incidence of dyslipidemia and to determine the value of Odds Ratio of risk factor for dyslipidemia. The research used case-control study design. The data were gathered from patients' medical records and from the respondents. The samples were 135 respondents with 45 of them were in case group and 90 of them were in control group. The result of bivariate analysis showed that all independent variables were correlated with the incidence of dyslipidemia $(p<0.05)$. The result of multivariate analysis showed that the variable which had the most dominant correlation was smoking habit at $\mathrm{p}$-value $=0.000(\mathrm{p}<0.05)$ and OR-value $=9.929(85 \%$ CI 3.428-28.762) which indicated that smoking habit was the most influential risk factor for the incidence of dyslipidemia in the elderly.
\end{abstract}

Keywords: The Elderly, Dyslipidemia, Gender, Obesity, Diabetes Mellitus, Smoking 


\section{PENDAHULUAN}

Data World Population Prospect the 2015 Revision, pada tahun 2015 ada 901.000 .000 orang berusia 60 tahun atau lebih, yang terdiri atas 12 persen dari jumlah populasi global. Pada tahun 2015 dan 20130, jumlah orang berusia 30 tahun atau lebih, yang diproyeksikan akan tumbuh sekitar 56 persen dari 901 juta menjadi 1,4 milyar dan pada tahun 2050 populasi lansia diproyeksikan lebih dari 2 kali lipat ditahun 2015, yaitu mencapai 2,1 milyar (United Nations, 2005).

Untuk mengupayakan penurunan jumlah kematian akibat PJK dan stroke badan kesehatan dunia menyarankan agar setiap negara membuat kebijakan untuk melakukan pencegahan terhadap kedua penyakit ini, karena meskipun banyak faktor risikonya sama untuk semua negara, namun ada perbedaan pendekatan antar negara dalam masalah budaya, sosial ekonomi dan juga ketersediaan obat. Kadar kolesterol darah yang tinggi (Dislipidemia) merupakan salah satu faktor risiko utama untuk terjadinya PJK dan stroke disamping Hipertensi, abnormalitas glukosa darah dan inaktifitas fisik (Badan Pusat Statistik, 2014).

Dislipidemia merupakan salah satu faktor risiko yang paling penting bagi banyak penyakit kronis yang tidak menular yang mengakibatkan morbiditas, mortalitas, dan biaya medis yang serius di seluruh dunia "State of the Art" (Singh A.K et al, 2011). Dislipidemia memiliki prevalensi yang tinggi hampir di seluruh negara di dunia, diantaranya Cina, tepatnya kota Beijing.

Prevalensi Dislipidemia menurut penelitian monitoring trends and determinants of cardiovascular disease (MONICA) yang menggunakan populasi usia 35-64 Tahun dari negara-negara Eropa, Australia, Selandia baru dan Kanada ditemukan sebanyak $25 \%$ pada pria dan 23 $\%$ pada wanita dengan rasio kolesterol total/HDL > 6 pada laki-laki dan > 5 pada wanita. Data di Indonesia yang diambil dari riset kesehatan dasar nasional (RISKESDAS) tahun 2013 menunjukkan ada $35,9 \%$ dari penduduk Indonesia yang berusia $\geq 15$ tahun dengan kadar kolesterol abnormal (berdasarkan NCEP ATP III, dengan kadar kolesterol $\geq 200 \mathrm{mg} / \mathrm{dl}$ ) dimana perempuan le $\mathrm{e}^{\mathrm{ii}}$ bih banyak dari lakilaki dan perkotaan lebih banyak dari pedesaan. Data RISKESDAS mempunyai proporsi LDL yang sangat tinggi $(\geq 500$ $\mathrm{mg} / \mathrm{dl}$ ) (Anwar TB, 2004).

Data dari dinas kesehatan kabupaten kampar tahun 2016, menunjukkan tingginya populasi lansia yakni 35.289 dari 785.941 total populasi, hal ini menunjukkan bahwa 22,2 \% populasi kabupaten kampar adalah lansia. Dinas kesehatan kabupaten kampar telah bekerjasama dengan Rumah Sakit Umum Daerah, rumah sakit swasta serta puskesmas untuk menggalakkan programprogram peduli lansia. Saat ini sudah banyak rumah sakit serta puskesmas yang berada di kabupaten Kampar telah dilengkapi dengan poli khusus lansia, hal ini dilakukan untuk mempermudah proses pengobatan pada lansia. Hal ini lah yang membuat peneliti sangat tertarik melakukan penelitian di RSUD Bangkinang kabupaten Kampar.

\section{METODE PENELITIAN}

Penelitian ini merupakan penelitian epidemiologi analitik dengan desain Case Control Study. Populasi dalam penelitian ini adalah seluruh lansia yang berobat ke Poli Lansia RSUD. Bangkinang Kabupaten Kampar. Adapun sampel dalam penelitian ini terdiri dari dua kelompok, yaitu kasus dan kontrol.Kelompok kasus adalah lansia yang berobat ke Poli Lansia RSUD.Bangkinang Kabupaten Kampar dan menderita dislipidemia, sedangkan kelompok kontrol adalah lansia yang berobat ke Poli Lansia RSUD.Bangkinang Kabupaten Kampar tetapi tidak menderita dislipidemia. Perbandingan kasus dan kontrol dalam penelitian ini adalah 1:2, yaitu 45 kasus dan 90 kontrol. Total sampel dalam penelitian ini adalah 135 sampel. Analisis data menggunakan analisis univariat, analisis bivariat dan analisis bivariat.

\section{HASIL PENELITIAN}

\section{Hubungan Usia dengan Kejadian Dislipidemia pada Lansia}

Hubungan usia dengan kejadian Dislipidemia pada lansia di Poli Lansia RSUD Bangkinang ditunjukkan pada tabel. 
Tabel 1.Hubungan Usia dengan Kejadian Dislipidemia pada Lansia di Poli Lansia RSUD Bangkinang tahun 2016

\begin{tabular}{|c|c|c|c|c|c|c|c|c|c|}
\hline \multirow{3}{*}{ Variabel } & \multicolumn{6}{|c|}{ Dislipidemia } & \multirow{3}{*}{ OR } & \multirow{3}{*}{$95 \%$ CI } & \multirow{3}{*}{$\begin{array}{c}p- \\
\text { value }\end{array}$} \\
\hline & \multicolumn{2}{|c|}{ Kasus } & \multicolumn{2}{|c|}{ Kontrol } & \multicolumn{2}{|c|}{ Total } & & & \\
\hline & $\mathbf{n}$ & $\%$ & $\mathbf{n}$ & $\%$ & $\mathbf{n}$ & $\%$ & & & \\
\hline Usia & & & & & & & & & \\
\hline 60-69 tahun & 36 & 42,4 & 49 & 57,6 & 85 & 100 & 3,347 & $1,445-7,753$ & 0,004 \\
\hline$>70$ tahun & 9 & 18,0 & 41 & 82,0 & 50 & 100 & & & \\
\hline
\end{tabular}

Berdasarkan tabe di atas, dapat dilihat dari 45 responden dari kelompok kasus terdapat 36 responden yang memiliki rentang usia 60-69 tahun, serta terdapat 9 responden yang memiliki rentang usia $>70$ tahun. Dari 90 responden dari kelompok kontrol, terdapat 49 responden yang memiliki rentang usia 60-69 tahun, serta 41 responden yang memiliki rentang usia $>70$ tahun.

Dari tabel tersebut diperoleh nilai $p$-value sebesar 0,004 $(p<0,05)$ yang artinya terdapat hubungan yang signifikan antara peningkatan usia dengan kejadian Dislipidemia. dari hasil analisis diketahui pula besar ORdari variabel Usia adalah 3,347 (95 \% CI 1,445-7,753), hal ini menunjukkan bahwa Usia memiliki risiko terhadap kejadian Dislipidemia sebesar 3,347 kali pada Lansia kelompok kasus dibandingkan dengan Lansia dari kelompok kontrol.

\section{Hubungan Jenis Kelamin dengan Kejadian Dislipidemia \\ Hubungan jenis kelamin terhadap kejadian Dislipidemia pada lansia di poli lansia RSUD Bangkinang ditunjukkan pada tabel.}

Tabel 2. Hubungan Jenis Kelamin dengan Kejadian Dislipidemia pada Lansia di Poli Lansia RSUD Bangkinang tahun 2016

\begin{tabular}{|c|c|c|c|c|c|c|c|c|c|}
\hline \multirow{3}{*}{ Variabel } & \multicolumn{6}{|c|}{ Dislipidemia } & \multirow{3}{*}{ OR } & \multirow{3}{*}{$95 \% \mathrm{CI}$} & \multirow{3}{*}{$\begin{array}{c}p- \\
\text { value }\end{array}$} \\
\hline & \multicolumn{2}{|c|}{ Kasus } & \multicolumn{2}{|c|}{ kontrol } & \multicolumn{2}{|c|}{ Total } & & & \\
\hline & $\mathbf{n}$ & & $\mathbf{n}$ & $\%$ & $\mathbf{n}$ & $\%$ & & & \\
\hline J. kel & & & & & & & & & \\
\hline Laki-laki & 19 & 28,8 & 47 & 71,2 & 66 & 100 & 3,348 & $1,481-7,566$ & 0,003 \\
\hline Perempuan & 26 & 37,3 & 43 & 62,3 & 69 & 100 & & & \\
\hline
\end{tabular}

Berdasarkan tabel di atas, diketahui bahwa dari 45 responden untuk kelompok kasus, 19 responden diantaranta adalah Laki-laki dan 26 responden diantaranya adalah perempuan. Hal ini menunjukkan bahwa perempuan lebih banyak mengalami Dislipidemia daripada laki-laki.Untuk kelompok kontrol yang berjumlah 90 responden, 47 diantaranya adalah laki-laki sedangkan 43 responden lainnya adalah perempuan.

Berdasarkan tabel diatas, diperoleh nilai $p$-value sebesar $0,003(\mathrm{p}<0,05)$ yang berarti Ho diterima. Sehingga disimpulkan bahwa ada hubungan yang bermakna antara jenis kelamin dengan kejadian Dislipidemia. Diketahui pula besar ORdari variabel Jenis Kelamin adalah 3,348 (95\% CI 1,481-7,566)artinya jenis kelamin memiliki risiko terhadap kejadian Dislipidemia pada Lansia di Poli Lansia RSUD Bangkinang.

Hubungan Obesitas dengan Kejadian
Dislipidemia pada Lansia Hubungan Obesitas dengan Kejadian Dislipidemia pada Lansia ditunjukkan pada tabel. 
Tabel 3. Hubungan Obesitas dengan Kejadian Dislipidemia pada lansia di Poli Lansia RSUD Bangkinang tahun 2016

\begin{tabular}{|c|c|c|c|c|c|c|c|c|c|}
\hline \multirow{3}{*}{ Variabel } & \multicolumn{6}{|c|}{ Dislipidemia } & \multirow{3}{*}{ OR } & \multirow{3}{*}{$95 \%$ CI } & \multirow{3}{*}{$\begin{array}{c}\text { p- } \\
\text { value }\end{array}$} \\
\hline & \multicolumn{2}{|c|}{ Kasus } & \multicolumn{2}{|c|}{ Kontrol } & \multicolumn{2}{|c|}{ Total } & & & \\
\hline & $\mathbf{n}$ & $\%$ & $\mathbf{N}$ & $\%$ & $\mathbf{n}$ & $\%$ & & & \\
\hline Obesitas & & & & & & & & & \\
\hline Tidak Obes & 18 & 17,6 & 84 & 82,4 & 102 & 100 & 3,200 & $1,381-7,416$ & 0,007 \\
\hline Obes & 27 & 81,8 & 6 & 18,2 & 33 & 100 & & & \\
\hline
\end{tabular}

Berdasarkan tabel di atas, diketahui bahwa dari 45 responden untuk kelompok kasus 18 responden diantaranya adalah responden yang tidak Obesitas, sedangkan 27 responden lainnya adalah responden yang pernah mengalami Obesitas. Dari 90 responden untuk kelompok kontrol, 84 responden diantaranya tidak pernah mengalami Obesitas dan 6 responden sisanya pernah mengalami Obesitas.

Dari hasil uji statistik diperoleh nilai $p$-value $0,007 \quad(\mathrm{p}<0,05)$ yang berarti terdapat hubungan yang bermakna antara Obesitas dengan kejadian Dislipidemia pada Lansia di Poli Lansia RSUD Bangkinang. Dari hasil analisis juga diperoleh nilai ORsebesar 3,200 (95\% CI 1,381-7,416), hal ini menunjukkan Obesitas memiliki risiko terhadap kejadian Dislipidemia pada Lansia di Poli Lansia RSUD Bangkinang sebesar 3,200 kali dibandingkan dengan lansia pada kelompok kontrol.

Hubungan Diabetes Melitus dengan Kejadian Dislipidemia pada Lansia Hubungan Diabetes Melitus dengan Kejadian Dislipidemia ditunjukkan dalam tabel di bawah ini.

Tabel 4..Hubungan Diabetes Melitus dengan Kejadian Dislipidemia pada Lansia di Poli Lansia RSUD Bangkinang tahun 2016

\begin{tabular}{|c|c|c|c|c|c|c|c|c|c|}
\hline \multirow{3}{*}{ Variabel } & \multicolumn{6}{|c|}{ Dislipidemia } & \multirow{3}{*}{ OR } & \multirow{3}{*}{$95 \% \mathrm{CI}$} & \multirow{3}{*}{ p-value } \\
\hline & \multicolumn{2}{|c|}{ Kasus } & \multicolumn{2}{|c|}{ kontrol } & \multicolumn{2}{|c|}{ Total } & & & \\
\hline & n & $\%$ & $\mathbf{N}$ & $\%$ & $\mathbf{N}$ & $\%$ & & & \\
\hline DM & & & & & & & & & \\
\hline Tidak DM & 5 & 6,1 & 77 & 93,9 & 82 & 100 & 3,500 & $1,511-8,105$ & 0,003 \\
\hline DM & 40 & 75,5 & 13 & 24,5 & 53 & 100 & & & \\
\hline
\end{tabular}

Berdasarkan tabel di atas, dari 45 responden dari kelompok kasus, terdapat 5 responden diantaranya tidak memiliki riwayat Diabetes Melitus dan 40 responden lainnya memiliki riwayat Diabetes Melitus. Dari 90 responden untuk kelompok kontrol, terdapat 77 responden yang memiliki riwayat Diabetes Melitus dan 13 responden lainnya memiliki riwayat Diabetes Melitus.

Berdasarkan table di atas, diperoleh nilai $p$-value sebesar $0,003(\mathrm{p}<0,05)$ artinya Diabetes Melitus memiliki hubungan yang signifikan dengan kejadian Dislipidemia.Dari hasil analisis diketahui juga bahwa nilaiORuntuk variabel Diabetes Melitus adalah sebesar 3,500 (95 \% CI 1,511-8,105), hal ini menunjukkan bahwa dalam penelitian ini, variabel Diabetes Melitus memiliki risiko terhadap kejadian Dislipidemia pada Lansia di Poli Lansia RSUD Bangkinang sebesar 3,500 kali dibandingkan lansia pada kelompok kontrol.

Hubungan Kebiasaan Merokok dengan Kejadian Dislipidemia pada Lansia Hubungan Kebiasaan Merokok dengan Kejadian Dislipidemia pada lansia ditunjukkan pada tabel di bawah ini. 
Tabel 5. Hubungan Kebiasaan Merokok dengan Kejadian Dislipidemia pada Lansia di Poli Lansia RSUD Bangkinang tahun 2016

\begin{tabular}{|c|c|c|c|c|c|c|c|c|c|}
\hline \multirow{3}{*}{ Variabel } & \multicolumn{6}{|c|}{ Dislipidemia } & \multirow{3}{*}{ OR } & \multirow{3}{*}{$95 \%$ CI } & \multirow{3}{*}{$\begin{array}{c}\text { p- } \\
\text { valu } \\
\text { e }\end{array}$} \\
\hline & \multicolumn{2}{|c|}{ Kasus } & \multicolumn{2}{|c|}{ Kontrol } & \multicolumn{2}{|c|}{ Total } & & & \\
\hline & $\mathbf{n}$ & $\%$ & $\mathbf{n}$ & $\%$ & $\mathbf{N}$ & $\%$ & & & \\
\hline $\begin{array}{c}\text { Kebiasaan } \\
\text { Merokok }\end{array}$ & & & & & & & & & \\
\hline Tidak Merokok & 16 & 28,1 & 41 & 71,9 & 57 & 100 & & $2,533-$ & \\
\hline Merokok & 29 & 37,2 & 49 & 62,8 & 78 & 100 & 6,048 & 14,444 & $\begin{array}{c}0,00 \\
0\end{array}$ \\
\hline
\end{tabular}

Berdasarkan tabel diatas, dapat dilihat bahwa dari 45 responden dari kelompok kasus, 16 responden tidak memiliki kebiasaan merokok dan 29 responden lainnya memiliki kebiasaan merokok. Dan dari 90 responden dari kelompok kontrol, 41 responden tidak memiliki kebiasaan merokok dan 49 responden lainnya memiliki kebiasaan merokok.

\section{Analisis Multivariat}

Setelah melewati beberapa tahap dalam analisis Multivariat, maka didapatkan faktor yang paling dominan terhadap kejadian Dislipidemia pada Lansia di Poli Lansia RSUD Bangkinang adalah Kebiasaan merokok, meskipun variabel usia, jenis kelamin, obesitas, diabetes melitus juga memiliki hubungan yang signifikan terhadap kejadian Dislipidemia, namun Kebiasaan Merokok merupakan variabel yang paling dominan dengan nilai $p$ sebesar $0,000 \quad(p<0,05)$ hal ini dapat diartikan bahwa Kebiasaan merokok memiliki hubungan yang signifikan dengan kejadian Dislipidemia pada Lansia, dan OR sebesar 9,929 (95 \% CI 3,428-28,762), dapat disimpulkan pula bahwa Lansia dari kelompok kasus dengan Kebiasaan Merokok memiliki risiko mengalami Dislipidemia sebesar 9 kali lipat dibandingkan kelompok kontrol.

\section{PEMBAHASAN}

Gambaran Kejadian Dislipidemia pada Lansia di Poli Lansia RSUD Bangkinang Dislipidemia adalah kelainan Metabolisme lipid yang ditandai dengan peningkatan kolesterol total, kolesterol LDL (Low Density Lipoprotein), Trigliserida diatas normal serta penurunan kadar kolesterol HDL (High Density Lipoprotein) di dalam darah.

Semakin tua usia seseorang maka fungsi organ tubuh semakin menurun, begitu juga dengan penurunan aktivitas reseptor LDL (Low Density Lipoprotein) sehingga bercak perlemakan dalam tubuh semakin meningkat dan menyebabkan kadar kolesterol total lebih tinggi, sedangkan kadar kolesterol HDL (High Density Lipoprotein) relatif tidak berubah.

Pada penelitian ini diketahui bahwa kejadian Dislipidemia paling banyak terjadi pada rentang usia 60-69 tahun (42,4\%). Hasil penelitian ini juga didukung oleh penelitian deksriptif dari Lesmana dkk pada tahun 2008 di Poli Penyakit Dalam RS Panti Rapih Yogyakarta, bahwa Dislipidemia pada Lansia kerap terjadi pada rentang usia 61-70 tahun. Usia dapat menjadi pemandu bagi seseorang dalam mengantisipasi kejadian Dislipidemia.

Hasil penelitian ini juga berbanding lurus dengan data dari RISKESDAS tahun 2013 dimana perempuan lebih sering menderita Dislipidemia daripada laki-laki. Pada penelitian ini didapatkan $37,3 \%$ dari kelompok kasus adalah perempuan, sementera penderita Dislipidemia laki-laki hanya $28,8 \%$.

Anwar TB pada tahun 2004 memperjelas faktor risiko jenis kelamin ini, dalam penelitiannya ia menuliskan bahwa risiko terjadinya Dislipidemia pada pria lebih besar daripada wanita. Hal tersebut karena pada wanita produktif terdapat efek 
perlindungan terhadap ateroklerosis dari hormon reproduksi yaitu estrogen, sedangkan pada pria lebih banyak menderita aterosklerosis karena hormon testosteron mempercepat timbulnya aterosklerosis.Akan tetapi pada wanita menopause mempunyai risiko lebih tinggi daripada wanita pre-menopause.

Tidak hanya usia dan jenis kelamin saja yang menjadi penentu terjadinya Dislipidemia pada lansia, bahkan pada orang yang mengalami obesitas (kelebihan berat badan) menunjukkan output VLDL (Very Low Density Lipoprotein), trigliserida yang tinggi dan kadar trigliserida plasma yang lebih tinggi. Trigliserida yang berlebihan dalam sirkulasi juga mempengaruhi lipoprotein lain. Bila trigliserida LDL dan HDL mengalami liposis akan menjadi small dense LDL dan HDL, abnormalitas ini secara tipikal ditandai dengan kadar HDL kolesterol.

Dalam penelitian ini ditemukan $37,2 \%$ subyek penelitian dari kelompok kasus yang memiliki kebiasaan merokok. Sedangkan hanya $28,1 \%$ saja yang tidak merokok. Namun angka yang tinggi juga dijumpai pada kelompok kontrol, 62,8 \% subyek adalah perokok.

\section{Hubungan Usia terhadap Kejadian Dislipidemia pada Lansia di Poli Lansia RSUD Bangkinang}

Dalam penelitiannya, Anwar TB (2004) menuliskan bahwa semakin tua usia seseorang maka fungsi organ tubuh semakin menurun, begitu juga dengan penurunan aktivitas reseptor LDL sehingga bercak perlemakan dalam tubuh semakin meningkat dan menyebabkan kadar kolesterol total lebih tinggi, sedangkan kadar kolesterol HDL relatif tidak berubah.

Hasil analisis statistik dari penelitian ini diperoleh nilai $\mathrm{p}$ untuk usia sebesar $0,004 \quad(\mathrm{p}<0,05)$ artinya usia memiliki hubungan yang signifikan dengan kejadian Dislipidemia pada Lansia di Poli Lansia RSUD Bangkinang. Dari hasil analisis didapatkan bahwa lansia beresiko 3,347 kali menderita Dislipidemia dibandingkan seseorang yang bukan dengan kelompok kontrol di Poli Lansia RSUD Bangkinang (95\% CI 1,445 - 7,753). Hasil ini didukung oleh penelitian yang dilakukan oleh Sugeha (2012) dimana ditemukan bahwa peningkatan usia (Lansia) beresiko 3,25 kali untuk terkena Dislipidemia, penelitian tersebut juga menggunakan disain Case Control Study.

Berdasarkan kelompok usia pada lansia, kelompok umur yang paling banyak terkenan Dislipidemia adalah kelompok umur 60-69 tahun, padahal menurut teori dan beberapa penelitian terdahulu bahwa semakin tua usia seseorang, maka semakin beresiko terkena Dislipidemia, namun hal itu tidak terbukti secara signifikan dalam penelitian ini, karena subyek penelitian dengan kelompok umur $>70$ tahun yang mengalami Dislipidemia hanya sebanyak $18,0 \%$.

Meskipun peningkatan usia merupakan faktor risiko Dislipidemia yang tidak dapat dimodifikasi, bukan berarti tidak dapat dilakukan upaya pencegahan. Justru dengan mengetahui faktor risiko yang dimiliki bisa membuat sesorang menjadi lebih berhati-hati untuk mengatur gaya hidup sehat agar terhindar dari Dislipidemia.

\section{Hubungan Jenis kelamin terhadap Kejadian Dislipidemia pada Lansia di Poli Lansia RSUD Bangkinang}

Anwar TB (2004) dalam penelitiannya menyebutkan bahwa untuk kesehatan tubuh yang optimal, range lemak tubuh untuk laki-laki adalah 10-25 \%, sedangkan perempuan $18-30 \%$ didasari atas beberapa penelitian epidemiologis untuk masyarakat umum. Distribusi lemak tubuh berbeda berdasarkan jenis kelamin.Risiko terjadinya Dislipidemia pada laki-laki lebih besar daripada perempuan.Hal tersebut karena pada perempuan produktif terdapat efek perlindungan terhadap aterosklerosis dari hormon reproduksi yaitu estrogen.Sedangkan pada pria lebih banyak menderita aterosklerosis karena hormon testosteron mempercepat timbulnya aterosklerosis. Akan tetapi pada wanita menopause mempunyai risiko lebih tinggi daripada wanita pre-menopause.

Dari penelitian ini ditemukan bahwa perempuan lebih banyak mengalami 
Dislipidemia daripada laki-laki, yaitu 57,7 $\%$ adalah perempuan dan $42,2 \%$ adalah laki-laki. Responden perempuan dalam penelitian ini sudah mengalami menopause, keadaan ini semakin membenarkan teori yang disebutkan oleh Anwar TB (2004) diatas.

Pada penelitian ini, diperoleh nilai p $0,003(p<0,05)$ artinya jenis kelamin memiliki hubungan yang signifikan terhadap kejadian Dislipidemia pada Lansia di Poli Lansia RSUD Bangkinang. Dari hasil analisis diketahui juga bahwa jenis kelamin tidak berisiko terhadap kejadian Dislipidemia pada lansia di Poli Lansia RSUD Bangkinang Kabupaten Kampar dengan nilai $O R$ sebesar 3,348 (95\% CI 1,481-7,566) jenis kelamin memiliki risiko terhadap kejadian Dislipidemia pada Lansia di Poli Lansia RSUD Bangkinang.

Gambaran jenis kelamin pada kelompok kasus dan kontrol masih bisa dibandingkan, pada kelompok kasus sebanyak 57,7 \% adalah perempuan, sementara pada kelompok kontrol lebih didominasi oleh laki-laki yaitu sebanyak $52,2 \%$. Tidak banyak penelitan yang membuktikan besarnya risiko jenis kelamin terhadap kejadian Dislipidemia, Nurzahman (2013) pernah menuliskan dalam penelitiannya bahwa perempuan yang telah memasuki usia menopause memang jauh lebih berisiko menderita Dislipidemia daripada perempuan yang belum memasuki usia menopause.

\section{Hubungan Obesitas terhadap Kejadian Dislipidemia pada Lansia di Poli Lansia RSUD Bangkinang}

Menurut Suiraoka IP (2012) dalam sebuh buku bahwa secara ilmiah, obesitas terjadi akibat ketidakseimbangan antara asupan kalori lebih banyak dari yang diperlukan oleh tubuh. Penyebab obesitas ada yang bersifat dari dalam (Endogenous) yang berarti adanya gangguan metabolik di dalam tubuh, dan ada pula yang bersifat dari luar (Eksogenous) yaitu konsumsi energi yang berlebihan, salah satunya adalah lemak hewani.

Hasil Analisis pada penelitian ini menunjukkan nilai $\mathrm{p}$ untuk variabel Obesitas adalah sebesar $0,005 \quad(p<0,05)$ artinya Obesitas memiliki hubungan yang signifikan dengan Kejadian Dislipidemia pada Lansia di Poli Lansia RSUD Bangkinang. Dari hasil penelitian dapat diketahui pula bahwa obesitas beresiko terhadap kejadian Dislipidemia pada lansia di Poli Lansia RSUD Bangkinang Kabupaten Kampar dengan nilai $O R$ sebesar 3,200(95\% CI 1,381-7,416) .

Gambaran obesitas pada kelompok kasus dan kontrol masih bisa dibandingkan, sebanyak $60 \%$ dari kelompok yang menderita Dislipidemia juga mengalami obesitas. Sedangkan pada kelompok kontrol yang mengalami obesitas jauh lebih sedikit yaitu $6,6 \%$.

Menurut konsep kausalitas Hill sebuah hubungan kausalitas juga harus bersifat temporal.Dimana paparan mendahului efek atau penyakit.Seringkali peningkatan berat badan berlebih muncul disaat yang bersamaan dengan terjadinya Dislipidemia, sehingga untuk melihat obesitas sebagai faktor risiko Dislipidemia harus dipastikan bahwa seseorang mengalami peningkatan berat badan terlebih dahulu sebelum menderita Dislipidemia. Pada Penelitian ini, riwayat peningkatan berat badan diketahui berdasarkan pengakuan dan ingatan responden.

Penelitian ini sejalan dengan penelitian yang dilakukan oleh Sugeha (2012) dimana orang dengan kelebihan berat badan berisiko 3,75 kali menderita Dislipidemia (95 \% CI 1,257-4,357). Penelitian tersebut menggunakan disain penelitian yang sama dengan penelitian ini, perbedaan ini kemungkinan terjadi akibat bias ingatan pada subyek dalam penelitian ini.

\section{Hubungan Diabetes Melitus terhadap Kejadian Dislipidemia pada Lansia di Poli Lansia RSUD Bangkinang}

Nurzahman (2013) menyebutkan

dalam penelitiannya bahwa Diabetes Melitus dalah suatu sindromapenyakit metabolisme yang ditandai dengan hiperglikemia. Penderita DM tipe 2 biasanya mengalami Dislipidemia kecuali bila dibawah kontrol glukosa yang baik.Penderita DM tipe 2 mempunyai 
beberapa abnormalitas lipid, meliputi peningkatan trigliserida plasma karena peningkatan VLDL dan lipoprotein remnant, peningkatan LDL dan penurunan HDL kolesterol.

Dari hasil analisis diperoleh nilai $\mathrm{p}$ untuk Diabetes Melitus sebesar 0,003 $(\mathrm{p}<0,05)$ hal ini menunjukkan bahwa Diabetes Melitus memiliki hubungan yang signifikan dengan Kejadian Dislipidemia. Pada penelitian ini diketahui pula bahwa Diabetes Melitus memiliki risiko terhadap kejadian Dislipidemia pada lansia di Poli Lansia RSUD Bangkinang Kabupaten Kampar. Dengan nilai $O R$ sebesar 3,500 $(95 \%$ CI 1,511-8,105).

\section{Hubungan Kebiasaan Merokok terhadap Kejadian Dislipidemia pada Lansia.}

Kebiasaan merokok disebut dapat menjadi faktor risiko kejadian Dislipidemia, Hayati (2009) menyebutkan dalam penelitiannya bahwa merokok menyebabkan peningkatan rasio metablisme dan cenderung untuk menurunkan intake makanan dibandingkan orang yang tidak merokok. Merokok dapat meningkatkan kadar kolesterol HDL dalam darah. Prevalensi merokok setiap hari lebih tinggi pada usia produktif (25-64 tahun) dan insidensinya pada laki-laki 11 kali lebih tinggi dibandingkan perempuan. Seseorang yang merokok 20 batang sehari dapat mempengaruhi atau memperkuat faktor risiko lainnya yaitu kadar lemak, hipertensi atau gula darah yang tinggi untuk jangka panjang, perokok berat (lebih dari 20 batang sehari) akan mengalami hipo-HDLKolesterolemia.

Dari hasil analisis diperoleh nilai $\mathrm{p}$ untuk variabel Kebiasaan Merokok sebesar $0,000(\mathrm{p}<0,05)$ hal ini menunjukkan bahwa Kebiasaan Merokok memiliki hubungan yang signifikan dengan Kejadian Dislipidemia. Pada penelitian ini, diketahui bahwa kebiasaan merokok sangat berisiko terhadap kejadian Dislipidemia pada lansia di Poli Lansia RSUD Bangkinang Kabupaten Kampar. Dengan nilai $O R$ sebesar 6,048(95 \% CI 2,533-14,444) kebiasaan merokok memiliki risiko terhadap kejadian Dislipidemia pada Lansia di RSUD Bangkinang.
Penelitian ini berbanding lurus dengan penelitian yang dilakukan oleh Lesmana (2008) dimana ditemukan bahwa orang yang memiliki kebiasaan merokok berisiko 2,00 kali menderita Dislipidemia (95\% CI 0,963-3,456) penelitian tersebut menggunakan disain yang sama dengan penelitian ini. Perbedaan ini kemungkinan terjadi akibat bias ingatan pada subyek dalam penelitian ini.

\section{KESIMPULAN DAN SARAN}

\section{Kesimpulan}

Berdasarkan hasil penelitian yang dilakukan terkait dengan faktor risiko Dislipidemia serta besar Odds Ratio nya terhadap kejadian Dislipidemia pada lansia di Poli Lansia RSUD Bangkinang Kabupaten Kampar pada Mei 2016-Mei 2017, maka diperoleh kesimpulan sebagai berikut :

1. Peningkatan usia memiliki risiko terhadap kejadian Dislipidemia pada lansia di Poli Lansia RSUD Bangkinang Kabupaten Kampar dengan besar OR 3,347 (95 \% CI 1,445-7,753).

2. Jenis kelamin memiliki risiko terhadap kejadian Dislipidemia pada lansia di Poli Lansia RSUD Bnagkinang Kabupaten Kampar dengan besar $O R$ 3,348 (95\% CI 1,481-7,566).

3. Obesitas memiliki risiko terhadap kejadian Dislipidemia pada lansia di Poli Lansia RSUD Bangkinang Kabupaten Kampar dengan besar $O R$ 3,200 (95\% CI 1,381-7,416).

4. Diabetes Melitus memiliki risiko terhadap kejadian Dislipidemia pada lansia di Poli Lansia RSUD Bangkinang Kabupaten Kampar dengan besar OR 3,500 (95\% CI 1,511-8,105).

5. Kebiasaan merokok memiliki risiko terhadap kejadian Dislipidemia pada lansia di Poli Lansia RSUD Bangkinang Kabupaten Kampar dengan besar OR 6,048 (95 \% CI 2,53314,444).

6. Berdasarkan analisa Multivariat, variabel yang paling dominan terhadap kejadian Dislipidemia adalah kebiasaan merokok dengan p-value $<0,05$ yakni 
0,000 dan $O R$ sebesar 9,929 (95\% CI 3,428-28,762).

\section{Saran}

\section{Bagi Masyarakat}

a. Hendaknya masyarakat lebih peduli terhadap kesehatannya sendiri dengan rutin memeriksakan kadar kolesterolnya ke fasilitas kesehatan terdekat, agar bisa dilakukan pengontrolan serta pengendalian terhadap faktor risiko yang bisa dimodifikasi.

b. Bagi lansia yang memiliki faktor risiko disarankan untuk lebih berhati-hati menjaga pola makan agar dapat meminimalisir gejala dari Dislipidemia.

\section{Bagi Rumah Sakit}

a. Diharapkan RSUD Bangkinang dapat meningkatkan program skrining faktor risiko Dislipidemia khususnya di Poli Lansia, dengan melakukan pengecekan secara rutin terhadap lansia yang datang berobat.

b. Diharapkan RSUD Bangkinang dapat meningkatkan program promosi kesehatan tentang faktor risiko Dislipidemia sehingga masyarakat menjadi cerdas dalam mengatur kesehatannya.

\section{Bagi Peneliti Lain}

a. Diharapkan kepada peneliti selanjutnya untuk melakukan penelitian lanjutan terhadap variabel kebiasaan merokok, jenis kelamin dan obesitas sebagai faktor risiko kejadian Dislipidemia.

b. Diharapkan kepada peneliti lain agar menjadikan lansia sebagai subyek penelitiannya, karena masih sedikitnya penelitian tentang faktor risiko Dislipidemia pada lansia.

\section{DAFTAR PUSTAKA}

Adam JMF. Dislipidemia.Dalam: Sudaya AW, Setiyohadi B, Alwi I, Simadibrata M, Setiati S. Buku
Ajar Ilmu Penyakit Dalam Ed.4.Jakarta:Interna Publishing, 2006; 1948-54

Ahmed SM, Clasen ME, Donelly JF. Dyslipidemia Management in Adult. Am Fam Physician. 2004 May 1;57(9);2192-2204. Available from:

http://.ncbi.nlm.nih.gov/pmc/.../PM C1492581

Al Kaabba A.F. et. al (2012). "Prevalence and Correlates of Dyslipidemia among Adults in Saudi Arabia :Results from a National Survey

Anwar TB. Dislipidemia sebagai Faktor Risiko Penyakit Jantung Koroner.Sumatera Utara: Fakultas Kedokteran USU. 2004; 1-15. Available from: http://www.library.usu.ac.id/downl oad/fk/gizi-bahri3.pdf

Badan Pusat Statistik. (2014). Statistik Penduduk Lanjut Usia. Diakses 15 april, 2017 dari http://www.bps.go.id/website/pdf_p ublikasi/Statistik-Penduduk-LanjutUsia-2014.pdf

Boedhi-Darmojo R. Bersama MONICA Melaksanakan Hidup Sehat.Bunga Rampai Karangan Ilmiah Prof. Dr. R. Boedhi-Darmojo. Semarang-FK Undip, 1994

Eckman, Ari. S. “ Type 2 Diabetes Mellitus “. Diakses dari :http://nlm.nih.gov/medlineplus/enc $\mathrm{y} /$ Article/000305.htm.2010

Fabiana et al .(2013). Correlation between Indicators of Abdominal Obesity and Serum Lipid in the Elderly"

Fatmah. (2010). Gizi Usia Lanjut.Jakarta: Penerbit Erlangga

Gandha N. Hubungan Perilaku Dengan Prevalensi Dislipidemia Pada Masyarakat Kota Ternate Tahun 2008.Jakarta: Fakultas Kedokteran UI. 2009; 5-13. Available from: http://www.lontar.ui.ac.id/file?file $=$ digital/122845-S09038fk...HA.pdf

Gibney MJ, Wolmarans P. Pedoman Diet. Dalam: Laurentia YS. Buku Gizi Kesehatan Masyarakat. Terjemahan: Andry Hartanto. Jakarta:EGC, 2008; 161-74. 
Goldstand et al. Type 2 Diabetes Mellitus : Priciples and Practice. NewYork: Informa Healthcare, 2008

Hayati N. Faktor-faktor Perilaku yang Berhubungan Dengan Kejadian Obesitas di Kelas 4 dan 5 SD Pembangunan Jaya Bintaro Tangerang Selatan Tahun 2009. Jakarta: Fakultas Kedokteran UI. 2009; 10-15. Available from: http://www.lontar.ac.id/file?file=digit al/124640-S-5871-Faktor...pdf

Herry, (2008).Hubungan Karakteristik, gaya hidup dan asupan faktor gizi terhadap status IMT pada lansia di 3 Posbindu Kelurahan Rangkapan Jaya Lama Kecamatan Pancoran Mas, Kota Depok: Fakultas Kesehatan Masyarakat Universitas Indonesia.

Hungu, 2007. Demografi Kesehatan Indonesia.Jakarata : Penerbit Grasindo

Infodatin Lansia.(2012). Situasi dan Analisis Lanjut Usia. Jakarta selatan (2016). Situasi Lanjut Usia di Indonesia. Jakarta selatan.

Ircham M. Tekhnik Menyusun Kuesioner \& Panduan Wawancara (Alat Ukur Penelitian Bidang Kesehatan, Kedokteran, Keperawatan dan Kebidanan.DI Yogyakarta: Fitramaya

Kaplan NM. Dalam: Laurentia YS. Primary Hypertension:

Pathogenesis,Mechanism of Hypertension with Obesity. In: Kaplan's Clinical Hypertension nineth edition. Philadelphia, USA: Lippincott W. 2006. 50-121

Kementrian Kesehatan RI (2014). Infodatin : Pusat data dan informasi kementrian kesehatan RI, Situasi dan analisis lanjut usia.

Kadar, K. S., Francis, K., \& Sellick, KDalam: Laurentia. YS. Ageing in Indonesia - Health Status and Challanges for the Future.Ageing International, 38(4), 2013. 261-270

Liberopoulus EN, Elisaf MS. Dyslipidemia in patinets with Thyroid Disorders.HORMONES International Journal of Endocrinology and
Metabolism [serial online]. 2002 Available from: http://www.hormones.gr/preview.php ?c $\_$id $=31$

Lesmana dkk, 2008.Hubungan antara kebiasaan Merokok dan Aktivitas Fisik pada Pasien Poli Penyakit Dalam di RS Panti Rapih Yogyakarta.

Mayes P. Sintesis,Pengangkutan, dan Ekskresi Kolesterol. Buku Biokimia Harper ED.25. Terjemahan: Andry Hartono. Jakarta: EGC, 2003;280

Novitasari, Dyah Y. Perbedaan profil Lipid dan Risiko Penyakit Jantung Koroner pada Penderita Diabetes Melitus tipe II Obesitas dan Non Obesitas Di RSUD Dr. Moewardi Surakarta.Surakarta. 2009; 1-4, Available from: http://www.etd.eprints.ums.ac.id/402 8/1/J310040017.pdf

Nurzahman dkk (2013).Faktor Risiko Pasien Dislipidemia di RS Arifin Achmad Pekanbaru Riau.

NHMRC, 2006.Nutrients Reference Values for Australia and New Zealand Including Recommended Dietary Intakes. Canberra and Wellington: National Health and Medical Research Council of Australia and Ministry of Health.

PB.Perkeni. Penatalaksanaan Dislipidemia. Buku Petunjuk Praktis Penatalaksanaan Dislipidemia. Perkumpulan Endokrinologi Indonesia. 2005; 5-14

Potter, P.A. \& Perry,A.G. (2005). Fundamental keperawatan: konsep, proses, dan praktik edisi 4 (Yasmin Asih, et al, Penerjemah). Jakarta:EGC

Stanley, Mickey. (2006). Buku Ajar Keperawatan Gerontik.(Juniarti, Nety et.al.,Penerjemah). Jakarta: EGC

Singh A.K. et al (2011). "Obesity and Dyslipidemia"

Suiraoka, IP. (2012). Penyakit Degeneratif; Mengenal, Mencegah dan Mengurangi Faktor Risiko 9 Penyakit 
Degeneratif.Yogyakarta:Nuha Medika

Soegondo S, Gustaviani R. Sindroma Metabolik. Dalam : Sudoyo Aru W.Setiyohadi B.Alwi I, Simadibrata M, Setiadi S,editors. Buku Ajar Ilmu Penyakit Dalam Ed. 4. Jakarta: Interna Publishing, 2006; 1849-51

Soekidjo N (2012). Metodologi Penelitian Kesehatan. Ed. Revisi. Jakarta: Rineka Cipta. 120-129

Soekirman.Ilmu Gizi dan Aplikasinya untuk Keluarga dan Masyarakat.Jakarta: Dirjen Dikti Depdiknas, 2000

Sondang S. (2012). "Perilaku Merokok pada siswa MTSN Model Kuok Kecamatan Bangkinang Barat Kabupaten Kampar Riau tahun 2012.

Sugeha. S. Dkk (2012). Faktor-faktor Risiko Dislipidemia pada Lansia dengan Obesitas Sentral di BPLU Manado.
Sujaya, I Nyoman."Pola Konsumsi Makanan Tradisional Bali sebagai faktor risiko Diabetes Melitus Tipe 2 di Tabana. ’.Jurnal Skala Husada Vol.6 No.1 (2009): 75-81

Steele et al. "Diabetes and Eye”. London: Elsevier Ltd,., 2008

Tan. X. J et al. (2008) “ Relationship between Smoking and Dyslipidemia in Western Chines Elderly Males.

United Nations.(2013). World Populating ageing 2013. Diakses 15 April, 2017,dari

http://www.un.org/en/developments /desa/populationpublications/pdf/ag eing/WorldPopulationAgeing2013. pdf

United Nations (2015). World Population prospect : The 2015 revision. Diakses 15 April, 2017, dari http://www.esa.un.org/unpd/wpp/p ublications/files/ key_findings_wpp_2015.pdf 